\title{
Processos Interacionais e a Construção de Conhecimento e Subjetividade de Crianças
}

\author{
Veriana de Fátima Rodrigues Colaço ${ }^{1}$ \\ Universidade Federal do Ceará
}

\begin{abstract}
Resumo
Este artigo propõe uma discussão teórica acerca dos processos interacionais infantis concebidos como mediadores para a construção de conhecimento e subjetividade. Tem como pressuposto a compreensão da atividade discursiva como processo que integra ação e linguagem e que se define como atividade mediada semioticamente, constituindo-se espaço de construção de conhecimento compartilhado. Os referenciais que embasam esta discussão estão pautados na teoria histórico-cultural de Vygotsky e na teoria da linguagem de Bakhtin, focalizando 3 categorias conceituais específicas: mediação semiótica, zona de desenvolvimento proximal e dialogia. O foco central da discussão volta-se para a temática da linguagem e dos processos de desenvolvimento cognitivo e subjetividade. A linguagem é abordada como inter-ação, dentro do enfoque da teoria da enunciação, e o desenvolvimento cognitivo e a construção da subjetividade compreendidos como resultantes dos intercâmbios da criança no seu contexto históricocultural, ou seja, linguagem, desenvolvimento e subjetivação como construções sociais.

Palavras-chave: Processos interacionais; mediação semiótica; zona de desenvolvimento proximal; subjetividade; dialogia.
\end{abstract}

\section{Children's Interactional Processes and the Production of Knowledge and Subjectivity}

This paper discusses children's interactional processes in terms of their mediation in the production of knowledge and subjectivity. Discoursive activity is conceived as a semiotically mediated process which integrates action and language, constituting a space of construction of shared knowledge. This discussion is based on Vygotsky sociohistorical theory and Bakhtin's theory of language, particularly on three specific concepts: semiotic mediation, zone of proximal development and dialogism. The argument focuses on themes of language and the processes of cognitive development and subjectivity. Language is understood on terms of the nature of interaction as presented in the theory of enunciation. Cognitive development and subjectivity production are viewed as a result of children's interchanges within their historical and cultural environment, that is, language, development and production of subjectivity are conceived as social constructions.

Keywords: Interactional processes; semiotic mediation; zone of proximal development; subjectivity; dialogism.

A análise que apresento neste artigo se refere a uma discussão teórica acerca dos processos interacionais infantis concebidos como mediadores para a construção de conhecimento e subjetividade. Essa análise parte da minha pesquisa de Tese de Doutorado em Educação, defendida em 2001, na qual investiguei a atividade discursiva de crianças em interação no contexto de sala de aula.

Tomo como pressuposto básico o caráter social do desenvolvimento humano, e foi nesta direção que procurei problematizar o processo investigativo empreendido na pesquisa de tese. Estando o sujeito inserido num ambiente de significações construídas numa determinada cultura, ou seja, num ambiente social e culturalmente organizado, o seu processo de construção de conhecimento e desenvolvimento não se realiza à margem, mas se gesta nas interações sociais. Isto é, nessa organização social e cultural encontram-se as possibilidades de produção de significados que alicerçam os

\footnotetext{
${ }^{1}$ Endereço para correspondência: Rua Henriqueta Galeno, 960, 201, Bairro Dionísio Torres, 60135 420, Fortaleza, CE. Fone: (85) 2582030; Fax: (85) 2887723. E-mail: verianac@uol.com.br
}

processos de humanização e subjetivação dos indivíduos. Como compreender, então, esse processo nas interações infantis desencadeadas em sala de aula? A especificidade deste contexto circunscreve discursos particularmente orientados para a atividade e aprendizagem escolar ou também estão sendo produzidos intercâmbios formadores de processos de subjetivação?

A base norteadora da argumentação dessas questões se apóia em autores como Vygotsky e Bakhtin e suas teorias do desenvolvimento e da linguagem, respectivamente. A afirmação de Vygotsky (1928/1998) de que "no processo do seu desenvolvimento, a criança não somente domina os conteúdos da experiência cultural, senão também os hábitos e as formas do comportamento cultural, os métodos culturais de raciocínio" (p. 31) fundamenta a idéia de que o conhecimento e a subjetividade são processos social e historicamente construídos. Destarte, conforme propõe Bakhtin (1929/2002), a linguagem é entendida como prática

\footnotetext{
${ }^{2}$ Todas as citações, cujos textos originais estão em espanhol, são traduções livres feitas pela autora do presente artigo.
} 
social, como uma produção eminentemente dialógica, por conseguinte, se faz na inter-ação e, neste sentido, tem papel mediador primordial para essa construção.

A interação social, a partir dessa problematização, tem um papel fundamental na discussão que pretendo levar adiante, posto que, numa concepção de construção social do sujeito e de compreensão da linguagem como ferramenta simbólica privilegiada de mediação, ela (a interação) constitui a base de todo esse processo. Interação não designando unicamente as relações explícitas (face a face) entre duas ou mais pessoas, mas condição inevitável e necessária de inserção social do indivíduo enquanto participante de um processo histórico e cultural que o produz e é, dialeticamente, também por ele produzido. Neste sentido, a interação é compreendida como condição de possibilidade da existência do sujeito, porque este só se constitui como tal na relação com os outros, a sua identidade se define na relação com a alteridade. Isto implica dizer que a interação está presente em qualquer temporalidade e em qualquer estado do sujeito, pois mesmo sozinho seu modo de agir, de pensar e de se articular com as coisas do mundo e com as pessoas estão pautados nos processos de significação cultural.

Também está sendo considerada a interação do sujeito com as ferramentas culturais (técnicas ou simbólicas) que ele domina e que se integram a sua ação, como bem explicou Wertsch (1999) em sua obra La Mente en Acción, referindo-se à atividade mediada pelo instrumento psicológico (ou signo) como o elo de ligação entre o agente e a ferramenta cultural, de tal sorte que não é possível isolar o agente e seus modos de mediação, que de forma integrada compõem a atividade mediada do sujeito. Assim, ao tratar da atividade discursiva -atividade mediada pelo signo- está sendo suposta a relação de imbricação entre ação e linguagem implicadas na interação humana.

Ao considerar a interação e a atividade discursiva é necessário ainda recorrer à compreensão dialógica da palavra, na acepção Bakhtiniana. O discurso (falado ou escrito) envolve necessariamente múltiplos sujeitos -falantes e ouvintes, locutores e interlocutores, ou escritores e leitores-, que orientam e definem os rumos da produção discursiva. Da mesma forma, o processo discursivo envolve falantes e ouvintes, cujos papéis se alternam nestas posições. O diálogo é a expressão viva desse jogo de papéis, delimitando os enunciados e organizando o processo de enunciação. Por conseguinte, em qualquer circunstância, a palavra é sempre dialógica, ela evoca significações que a antecedem, ao mesmo tempo em que desencadeia reações subseqüentes, que de alguma forma povoam as expectativas .do falante.

Assim, a concepção de atividade discursiva parte de uma abordagem sócio-cultural e dialógica, que coloca em foco o processo de interação concebido como: a) condição de subjetivação e essência da vida social humana; b) atividade mediada por ferramentas simbólicas; e c) produção discursiva/dialógica. Dentro deste contexto teórico estarão sendo tratados os processos de construção de conhecimento compartilhado e a produção de subjetividade, ou seja, esse embasamento dá sentido ao que será entendido como processos de desenvolvimento e subjetivação

Antes, porém, é importante esclarecer que, embora não se trate de um relato de pesquisa e sim de uma discussão teórica sobre a temática relativa a esses processos, neste artigo apresentarei excertos das falas das crianças que protagonizaram a minha pesquisa de tese, como exemplos ilustrativos. Contextualizando, explico que o trabalho empírico da tese foi realizado no ambiente escolar, com duas turmas do Ensino Fundamental de um colégio público federal, na cidade de Porto Alegre - RS. Com uma pesquisa de cunho etnográfico, no decorrer do ano letivo de 1999 foram focalizados diálogos de duas duplas de crianças em cada uma dessas turmas, ao realizarem tarefas escolares propostas pelas professoras (Colaço, 2001).

\section{Interação como Espaço de Construção de Subjetividade}

Considerando a análise que tentarei trazer neste texto, e após explicitar a minha compreensão acerca do conceito adotado sobre interação social, iniciarei tratando da dinâmica interativa na construção da subjetividade e, em seguida, analisarei a produção de novos conhecimentos construídos de forma compartilhada. Não se trata de pensar esses processos isolados e independentes; a subjetivação implica construção de conhecimento e vice-versa. No entanto, a intenção é de ressaltar quando um ou outro processo construtivo se explicita de forma mais contundente. É marcar o fenômeno de construção de subjetividade que se explicita nas atividades discursivas quando conteúdos específicos estão sendo veiculados nas interações sociais, e, no item seguinte, dar visibilidade aos processos de emergência de zona de desenvolvimento proximal (doravante usarei ZDP) que surgem nessas interações.

O contexto de sala de aula circunscreve um ambiente cultural específico, por um lado restritivo, porém também dinâmico, que explica a multiplicidade de sentidos subjacentes ao discurso escolar. Muitas vozes entram em ação, as quais se materializam nos enunciados dos professores e dos alunos. Vozes que não se limitam ao âmbito educacional, mas que ecoam também sentidos forjados em outros contextos culturais. Trata-se da polifonia e polissemia engendradas nas produções discursivas, uma vez que:

é no fluxo da interação verbal que a palavra se concretiza como signo ideológico, que se transforma e ganha diferentes significados, de acordo com o contexto em que ela surge. Constituído pelo fenômeno da interação social, o diálogo se revela como forma de ligação entre a linguagem e a vida. (Jobim e Souza, 1994, p. 120) 
Os discursos escolares, assim como os de outros contextos, evidenciam polifonia e dialogia, ao mesmo tempo em que emerge a singularidade do enunciador.Em parte é a palavra do enunciador e, em parte é a palavra do outro, numa dialética entre os planos individual e social, interpsicológico eintrapsicológico, na dinâmica de construção de sentido. Portanto, são discursos que comportam sentidos antecipados, confrontados, negociados ou até ignorados entre os interlocutores.

Estando submetidas às condições de possibilidade de um ambiente cultural particular, no cenário da sala de aula as produções discursivas apresentam peculiaridades e restrições que lhes são próprias, mas o discurso também contextualiza esse ambiente. Mercer (1998) afirma que através do discurso é possível a "contextualização contínua e cumulativa de eventos e a criação de um 'conhecimento comum' (que) são a própria essência da educação como processo psicológico e cultural." (p. 14). Ou seja, a dinâmica interna das ações e produções discursivas em sala de aula possibilita negociação e renegociação de sentido das atividades ali desenvolvidas. A sala de aula não é unicamente espaço de reprodução da cultura dominante e institucional; é também lugar de criação, de transformação e construção.

No que se refere às restrições discursivas do ambiente escolar, observa-se que os enunciados do professor apresentam uma conformação que expressa o seu papel docente. As perguntas retóricas, as afirmações recitativas, as acentuações expressivas de destaque aos conteúdos novos e significativos, etc, são formas discursivas, utilizadas com freqüência, que evidenciam a escolha do gênero discursivo (Bakhtin, 1979/1992) correspondente ao seu papel social. Por outro lado, na posição de aluno, as crianças apresentam formas enunciativas também características e as utilizam para expressar sua compreensão, suas dúvidas, etc. Elas participam das atividades escolares indicadas pelo professor e se expressam como aprendizes na situação escolar, bem como percebem a atuação orientadora do docente. Isto é, no imaginário das crianças está o papel do docente e também do que é esperado do seu modo de participação e expressão em sala de aula. São atribuições de papéis instituídos que configuram modelos relacionais e discursivos e seus protagonistas atuam e interagem em conformidade com esses modelos, pelo menos na maioria de suas experiências no espaço institucional escolar. Nesse contexto, vão se constituindo subjetivamente como alunos.

Porém, os papéis assumidos também se revestem de diferentes matizes nessa dinâmica cotidiana, especialmente no que tange à interação entre as crianças. No convívio de sala de aula, as crianças estabelecem entre elas relações de liderança, de colaboração, de competição, etc., que afetam a aparente estabilidade do papel que desempenham como aprendizes e dos gêneros de discurso esperados. Dependendo da orientação didática do professor, há um estímulo para a participação recíproca entre os discentes, podendo os alunos também atuarem como guia de outros membros do grupo. É interessante observar que, quando isso acontece, aqueles que orientam os colegas recorrem ao gênero do discurso docente.

Dois episódios ocorridos em ocasiões diferentes na situação da pesquisa podem ilustrar esse tipo de atuação, ao mesmo tempo em que apontam para a posição de liderança que é conquistada por algumas crianças na sua relação com as demais. Ambos se referem à orientação de uma das crianças sobre a tarefa de colegas que não estavam trabalhando com ela, mas que provavelmente lhe pediram ajuda.

\section{Excerto $\mathrm{n}^{0} 1$ - Turma de $\mathbf{1}^{\mathrm{a}}$ série}

Thais ${ }^{3}$ voltou-se para a dupla de crianças que estava atrás e que parecia ter pedido ajuda.

Thais: Tem sim, ó... (pegou o papel dos colegas). Você tem que pintar, ó... O avião amarelo vai na frente de... Você tem que pintar o amarelo aqui, o outro é vermelho (ia indicando para os colegas, que prestavam atenção à explicação dela). $\mathrm{Na}$ frente do...tem que pintar... É sim, ó..., entre os aviões amarelo e verde está o vermelho. Aqui, tu tem que fazer o seguinte, ó... Exercício: complete as frases (lendo a explicação do item). É assim, ó! Na frente do menino vai o gato. Atrás do menino vai o cachorro. Entre o gato e o cachorro vai o menino.

\section{Excerto n ${ }^{0} 2$ - Turma de $1^{\text {a }}$ série}

Carla fez uns enfeites nos chocolates que estavam na fileira de baixo. Em seguida, as duas viraram-se para os colegas da mesa de trás.

Thaís: Ai, Patrícia... Primeiro tem que enfeitar... (mostrou o seu papel à colega de trás) para depois recortar e colar os chocolates.

Carla: A Patrícia fez tudo errado, né? (dirigiu-se ao colega que estava trabalhando com Patrícia) Tu tem que ajudar ela...

A função de auxiliar os colegas era assumida por Thaís e bem aceita pelos demais, que a escutavam com atenção. Essa atitude de Thaís, além de ser possível porque propiciada (nessa turma específica) pela dinâmica incentivadora do intercâmbio e colaboração entre as crianças nas atividades escolares, revelava uma posição de liderança, que refletia características pessoais daquela criança, mas também essa posição era reforçada e legitimada pelo seu bom desempenho escolar. Seus enunciados, sua postura e a postura dos colegas retratavam uma situação típica de interação docente-discente,

${ }^{3}$ Foram reproduzidos os mesmos nomes fictícios das crianças utilizados no texto da Tese de Doutorado. 
no que se refere aos papéis desempenhados na relação e aos gêneros discursivos assumidos.

Por sua vez, o comentário feito por Carla ao final do diálogo -“Tu tem que ajudar ela..."- para o garoto que trabalhava em conjunto com Patrícia, indica que ela atentava para o papel que, ao invés de Thaís, o garoto deveria assumir, orientando a colega que estava ao seu lado. Carla expressa, com esse comentário, a referência à outra voz (da professora desta turma, especialmente), que orientava para o trabalho em parceria, onde o colega que melhor compreende a tarefa auxilia o outro numa atividade de construção compartilhada. Neste contexto, as vozes de Thaís e de Carla serviam de ventríloquo 4 à voz da professora, evidenciando o caráter polifônico dos enunciados, assim como modos de subjetivação envolvidos nas produções discursivas infantis. Isto porque, nessa dinâmica de interação entre as crianças, algumas conquistam legitimidade para auxiliar a outra, não apenas pela competência revelada em relação a determinado conteúdo, mas também pela negociação de papéis que vai se dando no cotidiano escolar. Portanto, formas de liderança se desenvolvem entre elas, que contribuem para a manutenção e reafirmação dessa legitimidade, por vezes conquistada mais pela força argumentativa de seus discursos do que pelo domínio do conteúdo.

Um outro episódio dos diálogos das crianças serve para ilustrar essa conquista de legitimidade. $\mathrm{O}$ excerto abaixo foi retirado de uma discussão entre Guilherme e Nestor que se passou no primeiro dia de filmagem com os mesmos, enquanto eles realizavam uma tarefa de escrita. Naquele momento -início do ano letivo de uma primeira série-, as crianças ainda se encontravam em processo de conhecimento mútuo e, após um primeiro movimento de orientação de Nestor sobre a escrita de Guilherme, este último iniciou um diálogo sobre um conteúdo (operação matemática) diferente da tarefa que estavam realizando.

\section{Excerto $\mathbf{n}^{\mathbf{0}} 3$ - Turma de $\mathbf{1}^{\mathbf{a}}$ série}

Guilherme:Vaca...ca...o quê?

Nestor: Ca...vaca ...vai v com a, igual a va-ca. V e o a...vaca. Agora só falta eu pintar.

Guilherme: Nestor...tu sabe quanto é um mais um? Sabe? Nestor: Sei, um mais um é igual a dois.

Guilherme: Não é três, anta. Um mais um é igual a dois. Três mais três dá...dá dois.

\footnotetext{
${ }^{4}$ Esse termo é usado por Wertsch, e ele o explica afirmando: "A intenção e o acento que possui uma expressão não são casuais. Por outro lado, não são meramente selecionados ou criados por um sujeito falante que trabalhe isolado. Antes ao contrário, refletem a intenção e o acento de outras vozes. Isto se produz por meio da 'ventriloquação' (Bakhtin, 1981; Holquist, 1981), isto é, o processo mediante o qual uma voz fala através de outra." (Wertsch, 1993, p. 142)
}

Nestor: Eu disse dois

Guilherme: Três mais quatro dá sete.

Nestor: Um mais um dá dois; três mais três dá seis.

Guilherme: Quatro mais quatro dá...?

Nestor:Dá oito.

Guilherme: Dez mais dez dá mil.

Nestor: Vinte.

Guilherme: Dá mil, eu disse mil.

Nestor: Não, vinte.

Guilherme: Mas eu pensei que tu falasse mil. O pé do patinho é laranja (referindo-se ao desenho do patinho na folha da tarefa).

O conteúdo matemático foi introduzido por Guilherme sem uma aparente explicação (a tarefa referia-se à produção de texto), no entanto, é possível supor, pelo desenrolar do diálogo, que o fato de Nestor demonstrar um conhecimento ainda não dominado completamente por Guilherme (a escrita) levou-o a desafiá-lo noutros domínios, num nível em que ele (Guilherme) saberia avaliar a correção da resposta, como o fez neste enunciado: "Não é três, anta. Um mais um é igual a dois." Assim, ele prossegue no seu questionamento como uma forma de testar a competência do colega. Neste diálogo, percebe-se ao mesmo tempo um conteúdo escolar que é compartilhado e o jogo de papéis negociados na dinâmica discursiva. Quando Nestor (assumindo um papel de professor) orientou Guilherme sobre como escrever, Guilherme inverteu essa posição, questionando o colega sobre um outro conteúdo -"Nestor...tu sabe quanto é um mais um? Sabe?"-, cuja resposta ele tinha conhecimento, ou seja, fez um tipo de pergunta retórica comumente usada no discurso docente. Portanto, não apenas o conteúdo é apreendido, mas padrões de comunicação e de relações sociais são compartilhados e negociados na atividade discursiva.

A riqueza e o dinamismo das interações que se passam na sala de aula são reveladores do modo como esse ambiente contextual se apresenta enquanto espaço de limites e possibilidades criativas, como um lugar onde não apenas os conteúdos curriculares estão sendo aprendidos e construídos, mas também a cultura escolar vai sendo apropriada pelos seus atores (professores e alunos) e ao mesmo tempo eles podem subverter os padrões e as expectativas préestabelecidas: as posições de liderança, de orientação, de apoio das aprendizagens também são exercidas por alunos num jogo discursivo e de negociação de papéis. Tanto os mecanismos de reprodução sociocultural como os de subversão são mediatizados pela linguagem, são significados e ressignificados através da comunicação verbal. Nesse processo, condições de subjetivação vão sendo engendradas nas interações humanas, em especial nas interações infantis que se formam no ambiente de sala de aula. 


\section{A Construção Compartilhada de Conhecimentos}

Da mesma forma que os processos de subjetivação são constituídos nesses eventos interativos, as atividades discursivas promovem a veiculação e construção compartilhada de conhecimentos. Esse espaço simbólico de intercâmbio pode viabilizar a emergência de $\mathrm{ZDP}$ e, conseqüentemente, tem um papel preponderante no contexto do ensino, no qual professores e estudantes se envolvem e compartilham dessa construção.

As situações de realização conjunta das tarefas escolares promovem uma situação propícia à produção de atividades discursivas, que implicam mediação simbólica. Ou seja, enquanto fazem as tarefas conjuntamente as crianças falam a respeito da mesma, perguntando, explicando, explicitando, comentando, etc. Seus enunciados não apenas acompanham a realização da atividade, mas a orientam, num sentido planejador e de apoio. Essa função mediadora dos discursos que acompanham as ações de uma criança repercute também nas ações da outra, mesmo quando não há uma intencionalidade explícita de ajuda.

Também sobre esse aspecto alguns excertos dos diálogos das crianças da pesquisa servem de ilustração dessa função planejadora e mediadora da linguagem no contexto escolar. Um deles reproduz o diálogo de uma das duplas de crianças da segunda série quando elas faziam uma tarefa envolvendo o aprendizado do sistema decimal. Ao tentarem solucionar um problema matemático de separação de quantidades utilizando palitos de picolé, Mariana e Paula contavam oralmente os palitos, enquanto os separavam em conjuntos de dez. Mariana orientava a colega neste processo, ao mesmo tempo em que sua contagem também guiava sua ação.

\section{Excerto $n^{\circ} 4$ - Turma da $2^{a}$ série}

Mariana: Calma, conta. Paula, separa assim... Bota nesse pratinho aí.

Paula: Não, Mariana, tu tem onze e eu só tenho dez.

Mariana: Olha, conta: um, dois, três, quatro, cinco, seis, sete, oito, nove, dez. E você, olha: um, dois, três, quatro, cinco, seis, sete, oito, nove, dez.

Paula: Olha aqui, Mariana (mostrou para a colega um palito que havia sobrado e estava fora do pratinho, no qual colocavam o conjunto de palitos).

Mariana: Porque tu já botou esse daqui, né? Um, dois, três, quatro, cinco, seis, sete, oito, nove, dez (recontou os palitos da colega).

Paula: Não, olha, um, dois...

Mariana: Calma, calma.

Paula: Peraí.

$\mathrm{E}$ as duas contaram juntas até dez, separando os conjuntos de palitos.
O problema proposto pela professora era de separar os palitos em conjuntos de 10 para encontrar o valor total do monte de palitos dados que envolvia dezenas e unidades. A contagem verbal acompanhava a ação de separar os palitos, mediando a atividade de ambas na direção da resolução do problema. Mariana usava a fala para demonstrar à colega a exatidão de sua contagem. Mas essa sua atitude não tinha essa única função e, sim, servia também de mediação para a resolução do problema e auxiliava a outra na compreensão do mesmo. Ou seja, as crianças expressavam verbalmente a operação que realizavam, mediando a ação através dos seus enunciados. $\mathrm{E}$ assim o faziam, face à necessidade de explicarem uma para a outra o modo de resolução da tarefa. Esse episódio é revelador do modo como as crianças dialogam sobre o raciocínio que empregam para a resolução dos problemas escolares e, com isso, também antecipam o passo seguinte a ser dado. A interação estabelecida na realização conjunta da tarefa favorece esse processo construtivo, no qual as produções dialógicas ou atividades discursivas são constitutivas e promotoras das aprendizagens e dos conhecimentos compartilhados.

Os processos de soletração e silabação operam nas tarefas relativas à escrita como uma estratégia semelhante à contagem oral nos problemas matemáticos. As crianças emprestam uma entonação bastante significativa a sua fala, indicando a sonoridade das letras e das silabas enfatizadas. Isto é, na contagem oral e na soletração ou silabação, as crianças expõem os modos de construção da atividade, seja a operação matemática ou a escrita da palavra. Assim, antecipam para elas próprias e para as colegas as ações seguintes, integrando discurso e atividade num sistema de mediação semiótica. Os espaços simbólicos de emergência de ZDP são postos em ação.

O excerto abaixo, referente a outro diálogo entre Thaís e Carla, quando elas realizavam uma tarefa de produção de um texto a partir do que lembravam sobre uma peça teatral assistida pela turma no dia anterior, éilustrativo dessa forma de mediação utilizando a silabação.

\section{Excerto $\mathrm{n}^{\mathrm{0}} \mathbf{5}$ - Turma de $\mathbf{1}^{\mathrm{a}}$ série}

Thaís: Ou ba...ba...c, tem o i ba...bactéria (silabando).

Carla: Que é...(incompreensível).

Thaís: Não sei, Carla, pensa.

Carla: A última parte.

Thaís: Babactéria.

Carla: Ba...bac...téria (silabando).

Thais: Babactéria.

Carla: Tinha que ter um i.

Thaís: Não...

Carla foi convidada pela professora a escrever a palavra no quadro e escreveu "bacitéria". 
Thaís: Não é assim, tá tudo errado. É baba c téria. Tu nem botou o a pra fazer o ba...ba. Nem botou o a no segundo. Carla, já tá errado. Porque ela botou o i.

A silabação, assim como a contagem numérica oral, são, portanto, recursos estratégicos reveladores da função mediadora da linguagem. As produções discursivas desencadeadas nesse contexto interacional demarcam os processos interpsicológicos de construção dos conhecimentos que são apropriados por cada criança. Ao representar simbolicamente suas ações através da linguagem, as crianças reorganizam o seu raciocínio e compartilham entre elas suas novas construções.

Vygotsky (1934/1993) explica que o pensamento se reestrutura com a linguagem, isto é, ele se realiza nela. A linguagem não funciona apenas como expressão do pensamento, mas o transforma. Os estudos de Luria (1960/ 1991, 1995) vêm reforçar esta idéia da função reguladora da linguagem. Ele enfatiza que a palavra, não é apenas instrumento de pensamento, mas também funciona na regulação dos processos psíquicos superiores. Em suas palavras: "A atividade verbal, além de ser um meio de generalização e uma fonte de pensamento, é também um meio para regular o comportamento." (1960/1991, p. 81)

Esses processos de compartilhamento da atividade e mediação semiótica potencializam o surgimento de situações de emergência de ZDP, esta compreendida não como uma capacidade individual, mas sim como espaço simbólico que promove a construção do conhecimento para as crianças que participam do evento interativo.

A emergência de ZDP como espaço simbólico de construção compartilhada, também pode ser elucidada num outro episódio relativo ao diálogo entre Carla e Thaís, quando elas escreviam um texto interpretativo a partir da leitura de uma história em quadrinhos sobre a reciclagem do lixo. Embora, na primeira série ainda não fossem exploradas as regras da sintaxe gramatical, as duas tentavam encontrar a forma mais adequada de colocar o sujeito de uma frase e o emprego da conjugação do verbo.

\section{Excerto $\mathbf{n}^{\mathbf{0}}$ 6: Turma da $\mathbf{1}^{\mathbf{a}}$ série.}

Thaís: E agora escreve: nós entendemos que devemos separar o lixo orgânico e seco. E aprendemos também... Eu escrevo. Nós...

Carla: Não, não é nós...eu...

Thaís: Nós... Aí vamos fazer.

Carla: Como nós?

Thaís: Oito.

Carla: Nove.

Thaís: Oito.
Carla: Nove (esses números referiam-se à ordem dos quadrinhos que elas estavam sinalizando para a elaboração do texto).

Thaís: Então, o que nós vamos escrever? Eu e Carla...

Carla: Não. Eu quem? Thaís e Carla descobriram que...

Thaís: Peraí...

Carla: Que nós...

Thaís: Descobrimos que devemos. A Thaís...

Carla: E...

Thais: E... Carla. Eu e ...

Carla: Vai, tu que fala.

Thaís: Thaís e Carla descobrimos...

Carla: Descobriram.

Thais: Descobrimos, descobriram.

Carla: Tá, descobrimos...que devemos jogar o lixo no lixo... Que devemos separar o lixo. Que deve...

No início da elaboração do texto, a problematização levantada por Carla sobre o sujeito da frase, aponta para uma certa compreensão acerca da necessidade de maior clareza e explicitação de um texto escrito. Como iriam entregar à professora, era importante esclarecer quem era o "nós" ao qual estavam se referindo. E ao trocar o sujeito da frase, também o verbo deveria variar para concordar com o sujeito. Esse é um nível de elaboração que aponta para o início da conscientização da estrutura gramatical do texto, cujo aprendizado formal se dará posteriormente à primeira série, mas que a própria aquisição da lecto-escrita já antecipa, colaborada pela gramática interna da oralidade. Ao levantar essa discussão, Carla desencadeava um processo construtivo acerca da estrutura gramatical da frase, que ia além de seus próprios conhecimentos naquele momento de aprendizado escolar. Nesse espaço interacional, Thaís, capturando o sentido implícito da pergunta "Como nós?", feita por Carla, contribuiu para dar prosseguimento ao raciocínio que vinha sendo desenvolvido pela colega, assim como compartilhou do mesmo processo construtivo, proporcionado pelo diálogo estabelecido entre elas. A possibilidade de explicitação e discussão dessa referência ao aspecto gramatical do texto que escreviam contribuía para o avanço da escrita de ambas as crianças. Como nos ensina Bruner (2001), "a externalização resgata a atividade cognitiva do implícito, tornando-o mais palpável, negociável e 'solidário'. Ao mesmo tempo, ela o torna mais acessível a uma reflexão e metacognição subseqüentes.” (p. 32). Esse processo discursivo veiculado na interação das crianças, potencializa uma construção escrita mais elaborada do que estava sendo solicitado na tarefa, e representa a expressão do espaço simbólico de construção conjunta, potencializador de emergência de ZDP.

Vygotsky destaca a escrita como uma função especial da linguagem, uma vez que implica um nível elevado de 
abstração na sua produção. Isso porque a escrita envolve uma representação de segunda ordem, na medida em que o que se representa é o som da palavra e não o seu referente objetivo. Além disso, não há um interlocutor presente, ela se dirige a alguém ausente ou que não está em contato direto com quem escreve. Portanto, a escrita requer uma dupla abstração, que supõe processos mentais complexos. Ela exige da criança a consciência da estrutura fônica da palavra, para desmembrá-la e reproduzi-la em signos lingüísticos, bem como a consciência da estrutura sintática e semântica para a construção das frases. Conforme afirma esse autor:

É uma linguagem sem interlocutor, o que constitui uma situação completamente desacostumada para a conversação da criança... Se trata de uma linguagem-monólogo, da conversação com uma folha de papel em branco, com um interlocutor imaginário... A situação da linguagem escrita é uma situação que exige da criança uma dupla abstração: do aspecto sonoro e do interlocutor... Evidentemente, uma linguagem sem som real, que a criança se imagina e pensa, que exige a simbolização dos símbolos sonoros, quer dizer, uma simbolização de segundo grau, deverá ser tão difícil com respeito à linguagem oral como o é para a criança a álgebra com respeito à aritmética. (Vygotsky, 1934/1993, pp. 229-230)

Os diálogos desencadeados pelas crianças ao realizarem suas tarefas escolares conjuntamente possibilitam o compartilhamento das soluções dos problemas envolvidos nas tarefas, de modo que elas podem ir além de suas capacidades individuais. Nesses espaços interativos, portanto, acontecem as trocas interpsicológicas e as construções intrapsicológicas delas derivadas internalização/apropriação. Isto é, no processo interativo e discursivo enraíza-se a essência e toda a base da construção compartilhada de conhecimento, que evidencia os processos de mediação da linguagem e o surgimento da ZDP como espaço simbólico de possibilidades mais elaboradas e enriquecedoras da atividade.

\section{Considerações Finais}

A discussão até aqui desenvolvida pretendeu evidenciar que as interações entre os alunos podem mobilizar processos de ensino/aprendizagem tanto no que se refere aos conteúdos (curriculares, no caso do contexto escolar), quanto aos modos de convivência entre as pessoas. Isto significa que as crianças ensinam umas as outras e aprendem nos seus intercâmbios. Ensinam e aprendem conteúdos das matérias escolares, modalidades comunicacionais e de convivência, disciplinamentos referentes às normas de condutas sociais, características do ambiente cultural da escola, assim como desempenham, disputam e negociam papéis entre elas. Tendo como modelo de referência os modos interacionais que vivenciam com o professor, quando Psicologia: Reflexão e Crítica, 2004, 17(3), pp.333-340 interagem entre si, as crianças, em muitos aspectos os reproduzem, mas também os recriam. Ou seja, elas orientam, apóiam, dão respostas e inclusive avaliam e corrigem a atividade do colega, com o qual dividem a parceria do trabalho, assumindo posturas e gêneros discursivos semelhantes aos do professor. Os aprendizes auxiliam uns aos outros no aprender, cada um de acordo com suas competências particulares. Assim, eles servem de "andaimes", no dizer de Bruner (2001), uns para os outros; ou melhor, quando são promovidas situações de atividade conjunta entre os alunos, eles também podem se colocar na posição de sujeitos mediadores, favorecendo os espaços simbólicos de emergência de ZDP. Nesta dinâmica interpsicológica de negociações e interposições de papéis, de intercâmbio de conhecimentos, os processos de subjetivação e apropriação de conhecimentos são desenvolvidos, mediados pela linguagem.

As atividades discursivas no contexto de sala de aula são construções coletivas, nas quais os significados vão sendo produzidos e apropriados pelos que delas participam. Muitas vozes se entrecruzam na sua produção, vozes presentes no campo da enunciação (falante-ouvinte, numa relação transitória e mutante) e também aquelas de personagens ausentes, próximos ou distantes, que povoam o imaginário de cada um e que remetem à multiplicidade de outros contextos influentes nessa produção: familiar, institucional, cultural e social. Também elas (as atividades discursivas) são condicionadas pelas circunstâncias do momento concreto de sua ocorrência, dependente ainda do que se fala ou faz antes, bem como das expectativas do que pode ser dito ou feito posteriormente. Assim, uma atividade que tem uma intencionalidade pedagógica definida desencadeia modos de realização diferentes e promove construções e aprendizagens distintas, posto que estão submetidas a uma multiplicidade de circunstâncias influentes.

As relações sociais que estão na base da construção do conhecimento e do desenvolvimento da humanidade se materializam nas redes de interações, que acontecem nos cenários culturais particulares. Nesses cenários são viabilizadas as micro-relações, são tecidos os significados e os processos de construção compartilhada, possibilitando avanços e transformações, que repercutirão direta ou indiretamente nos níveis mais amplos das relações sociais. Por conseguinte, nas interações são criadas as condições de possibilidade de constituição dos sujeitos, singulares e, ao mesmo tempo, forjados no seu ambiente histórico-cultural.

\section{Referências}

Bakhtin, M. (1992). Estética da criação verbal (M. E. G. G. Pereira, Trad.). São Paulo: Martins Fontes. (Original publicado em 1979) 
Bakhtin, M. (V. N. Volochínov) (2002). Marxismo e filosofia da linguagem (M. Lahud \& Y. F. Vieira, Trads.) (10ª ed.). São Paulo, SP: HUCITEC. (Original publicado em 1929)

Bruner, J. (2001). A cultura da educaşão (M. A. G. Domingues, Trad.) Porto Alegre: ArtMed. (Original publicado em 1996)

Colaço, V. F. R. (2001). Interações em sala de aula: Um estudo da atividade discursiva de crianças em séries iniciais. Tese de Doutorado não-publicada, Curso de PósGraduação em Educação, Universidade Federal do Rio Grande do Sul. Porto Alegre, RS.

Jobim e Souza, S. (1994). Infäncia e linguagem: Bakbtin, Vygotsky e Benjamin. Campinas, SP: Papirus.

Luria, A. R. (1995). Conciencia y lenguaje ( $3^{\mathrm{a}}$ ed.). Madrid: Visor. (Original s/d)
Luria, A. R. (1991). O papel da linguagem na formação de conexões temporais e a regulação do comportamento em crianças normais e oligofrênicas. Em A. R. Luria, A. Leontiev, L. S. Vygotsky \& cols.(Orgs.), Psicologia e pedagogia: Bases psicológicas da aprendizagem e do desenvolvimento (R. E. Frias, Trad.; pp. 77-94). São Paulo: Moraes. (Original publicado em 1960)

Mercer, N. (1998). As perspectivas socioculturais e o estudo do discurso em sala de aula. Em C. Coll \& D. Edwards (Orgs.), Ensino, aprendiragem e discurso em sala de aula. Aproximações ao estudo do discurso educacional (R. A. Neves, Trad.; pp. 1328). Porto Alegre: Artes Médicas. (Original publicado em 1996)

Vygotsky, L. S. (1993). Obras escogidas, pensamiento y lenguaje. Conferencias sobre psicología (Vol. II). Madrid: Visor. (Original escrito em 1934)

Vygotsky, L. S. (1998). El desarrollo cultural del niño y otros textos ineditos. Buenos Aires: Almagestos. (Original publicado em 1928)

Wertsch, J. V. (1993). La voz de la racionalidad em un enfoque sociocultural de la mente. Em L.C. Moll (Org.), Vygotsky y la educación: Conotaciones y aplicaciones de la psicología sociobistórica en la educación. Buenos Aires: Aique.

Wertsch, J. V. (1999). La mente en accion. Argentina: Aique.

Recebido: 04/11/2003

Sobre a autora

Aceite Final: 23/12/2003

Veriana de Fátima Rodrigues Colaço é Psicóloga, Doutora em Educação pela Universidade Federal do Rio Grande do Sul. É Professora do Departamernto de Psicologia da Universidade Federal do Ceará. 